\title{
Transatlantic editorial on transcatheter aortic valve replacement
}

\author{
Vinod H. Thourani, MD, ${ }^{\mathrm{a}}$ Michael A. Borger, MD, PhD, ${ }^{\mathrm{b}}$ David Holmes, MD, ${ }^{\mathrm{c}}$ Hersh Maniar, MD, ${ }^{\mathrm{d}}$ \\ Fausto Pinto, MD, PhD, ${ }^{e}$ Craig Miller, MD, ${ }^{f}$ Josep Rodés-Cabau, MD, ${ }^{\mathrm{g}}$ \\ Friedrich-Wilhelm Mohr, MD, PhD, ${ }^{\mathrm{h}}$ Holger Schröfel, MD, PhD, ${ }^{i}$ Neil E. Moat, MBBS, MS, ${ }^{j}$ \\ Friedhelm Beyersdorf, MD, PhD, ${ }^{\mathrm{k}}$ G. Alexander Patterson, $\mathrm{MD},{ }^{1}$ and Richard Weisel, $\mathrm{MD}, \mathrm{PhD}^{\mathrm{m}}$
}

\footnotetext{
From the a Division of Cardiothoracic Surgery, Joseph B. Whitehead Department of Surgery, Emory University, Atlanta, Ga; ${ }^{b}$ Division of Cardiac Surgery, Department of Surgery, Columbia University, New York, NY; ${ }^{\mathrm{c} D e}$ partment of Cardiology, Mayo Clinic, Rochester, Minn; ${ }^{\mathrm{d}}$ Division of Cardiothoracic Surgery, Department of Surgery, Washington University; ${ }^{\text {DDepartment }}$ of Cardiology, University Hospital Santa Maria, University of Lisbon, Lisbon, Portugal; ${ }^{\mathrm{f}}$ Department of Cardiac Surgery, Stanford University, Palo Alto, Calif; ${ }^{\mathrm{g}}$ Quebec Heart \& Lung Institute, Laval University, Quebec City, Quebec; ${ }^{\mathrm{h}}$ Department of Cardiac Surgery, Leipzig Heart Center, Leipzig; ${ }^{\mathrm{i}}$ Clinic for Cardiac Surgery Karlsruhe; ${ }^{\mathrm{j}}$ National Institute Health Research Cardiovascular Biomedical Research Unit, Royal Brompton Hospital and Harefield National Health Service Foundation Trust, London, United Kingdom; ${ }^{\mathrm{k}}$ Department of Cardiovascular Surgery, Heart Centre Freiburg University, Freiburg, Germany; ${ }^{1}$ Division of Cardiothoracic Surgery, Department of Surgery, Washington University School of Medicine, St Louis, Mo; and ${ }^{\mathrm{m}}$ Division of Cardiovascular Surgery, Peter Munk Cardiovascular Center, Toronto General Research Institute, Toronto General Hospital and the University of Toronto, Toronto, Ontario, Canada. Dr Beyersdorf is the Editor of the European Journal of Cardiothoracic Surgery. Dr Patterson is the Editor of Annals of Thoracic Surgery. Dr Weisel is Editor of the Journal of Thoracic and Cardiovascular Surgery.

This article has been co-published with permission in The Journal of Thoracic and Cardiovascular Surgery, The Annals of Thoracic Surgery, and European Journal of Cardio-Thoracic Surgery.

Received for publication Jan 12, 2017; revisions received March 10, 2017; accepted for publication March 11, 2017.

Address for reprints: Vinod H. Thourani, MD, Emory Hospital Midtown, 550 Peachtree St, 6th Floor Medical Office Tower, Atlanta, GA 30308 (E-mail: vthoura@emory.edu).

J Thorac Cardiovasc Surg 2017;154:7-21

$0022-5223 / \$ 36.00$

Copyright (C 2017 Jointly between The American Association for Thoracic Surgery, the European Association for Cardio-Thoracic Surgery, and the Society for Thoracic Surgeons. Published by Elsevier Inc. All rights reserved. http://dx.doi.org/10.1016/j.jtcvs.2017.03.047
}

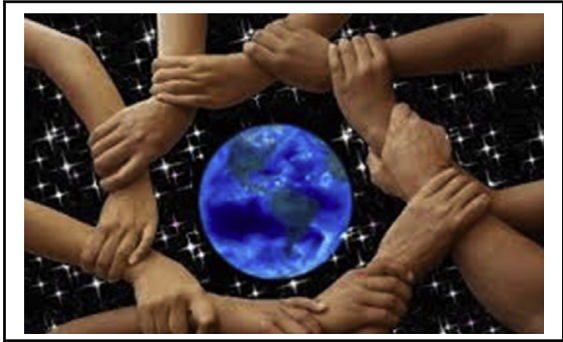

The treatment of aortic stenosis is changing rapidly, and sharing ideas from across the Atlantic will help us provide the most optimal care for our patients.

Central Message

The treatment of aortic stenosis is changing rapidly, and sharing ideas from across the Atlantic will help us provide the most optimal care for our patients.

\section{Perspective}

The management of aortic stenosis has expanded to include both surgical and transcatheter options. It remains important for the heart team to decide the most optimal patients for each treatment strategy.
Aortic stenosis (AS) is the most common acquired valve disease in elderly patients, with a prevalence of $2.8 \%$ in those 75 years or older. ${ }^{1}$ As the general population ages, ${ }^{2}$ it is reasonable to expect that the number of patients seeking treatment for AS also will increase in the coming years. Surgical aortic valve replacement (SAVR) remains the most effective treatment of AS and can be performed with excellent results. ${ }^{3-7}$ However, elderly patients increasingly are presenting with multiple comorbidities, making them either high- or extreme-risk surgical candidates. Transcatheter aortic valve replacement (TAVR) was developed as an alternative to SAVR for patients at high operative risk. Since the introduction of this transformative technology in 2002, TAVR has been found to be superior to standard medical therapy at 5 years in inoperable patients. ${ }^{8}$ In addition, mid-term results have revealed that TAVR is equivalent or has superior survival compared with SAVR in high-risk operative patients. 9,10 These findings, combined with the minimal invasive nature of TAVR, have resulted in an explosion in the number of these procedures performed in North America and
Europe. $^{11,12}$ A similar marked experience in the number of TAVR-related clinical studies also has been observed in the last few years, with several recent clinical trials even investigating the use of TAVR in intermediate- and low-risk patients. ${ }^{13,14}$

With such a rapidly developing landscape in the management of patients with severe $\mathrm{AS}$, recommendations that have been published by various medical societies may no longer accurately reflect current clinical practice. For example, valve guidelines produced by the European Society of Cardiology/European Association for CardioThoracic Surgery in 2012 listed bicuspid aortic valve disease and untreated coronary artery disease requiring intervention as relative contraindications for TAVR. ${ }^{15} \mathrm{How}-$ ever, increasing clinical experience suggest that TAVR can be performed in both of these scenarios (combined with percutaneous coronary intervention for the latter) with good results. ${ }^{16,17}$ As another example, the American Heart Association/American College of Cardiology guidelines from 2014 recommend SAVR as the procedure of choice for intermediate-risk patients with AS (class of 
recommendation I, level of evidence A). ${ }^{18}$ However, recent data have suggested that transfemoral (TF) balloonexpandable TAVR may be superior to SAVR in intermediate-risk patients. $^{13,14}$ Another randomized, prospective trial using the self-expanding TAVR valve compared with surgery in intermediate-risk patients is forthcoming.

In addition to the rapidly changing landscape for patients with AS, significant variations in clinical practice patterns-for a variety of causes-also can be observed between North America and Europe. For example, TAVR was being performed at a much more frequent rate in Germany than in the United States over the last few years. However, TAVR has increased rapidly in the United States and currently is being performed in $44.4 \%$ of patients requiring isolated aortic valve procedures, compared with $46.7 \%$ in Germany. With this background, the current document aims to evaluate the similarities and differences in the indications and patient populations currently undergoing SAVR and TAVR in Europe and North America. In addition, our multidisciplinary, international writing group aims to present an up-to-date overview of the current state of TAVR to further guide practice patterns and future areas of research within the greater cardiovascular community.

\section{THE ROLE OF THE HEART TEAM}

\section{Members and Qualifications of the Heart Team}

The Heart Team has become a central concept in modern cardiovascular disease. Team-based care has been a widely used approach in many medical and surgical fields such as oncology, solid-organ transplants, and neurovascular disease. However, it has reached a more integrated level with the inclusion of the Heart Team in the United States as a requirement by the Center for Medicare/Medicaid Services for reimbursement. In addition, in Europe it is codified in guidelines as a Class I indication for revascularization of patients with chronic stable angina and structural heart disease. The concept of bringing together a multidisciplinary team to reach a consensus in managing complex patients and thereby optimizing outcome is straightforward. Less straightforward is the make-up of and implementation of this multidisciplinary team in daily practice. Equally less straightforward are the metrics that can be used to judge the efficacy in clinical care.

With TAVR, the Heart Team seems intuitively obvious because the care of patients with structural heart disease such as AS crosses the boundaries of cardiac surgery and cardiology, each of which bring different expertise and experience to these complex patients. This is particularly true because both catheter-based as well as surgical skills are needed for patient selection, procedural techniques, and periprocedural management of complications should they occur. Both the U.S. and European guidelines are proponents of the Heart Team, with specific performance of TAVR in hospitals with cardiac surgery on-site.

\section{Components of the Heart Team}

Components of the TAVR Heart Team vary. At the present time, the core consists of the partnership between the interventional cardiologist and cardiac surgeon. As mentioned, this relationship has been codified for reimbursement but in actual fact provides merit. Other members of the Heart Team should include imaging specialists experienced with echocardiography and computed tomography (CT), cardiac anesthesia, nonprocedural cardiologists whose role will be to manage the patients pre- and postoperatively and also in terms of longer term care, as well as nursing care specialists and advanced practice providers for these high-risk patients with multiple comorbidities. Occasionally neurologists are required to help determine levels of preoperative dementia. The addition of a patient (or family advocate) may be very valuable in some circumstances to help synergize physician and patient expectations.

\section{Nodes of Interaction}

There are multiple areas and needs for interaction (Figure 1). Some of these may either occur or be met in structural space, others in the virtual reality of telemedicine. Essential points of contact include:

1. Evaluation of the patient with AS for the potential need for mechanical intervention. This requires evaluation of clinical patient demographics and the baseline assessment of hemodynamics as well as the degree, severity, and extent of comorbidities.

2. After evaluation as a candidate, the surgeon and cardiologist should decide on the risk benefit ratio of the relative merits for medical therapy or aortic valve replacement via the TAVR or SAVR techniques.

3. Discussion with the patient and family by both surgeon and cardiologist about options available and educating the patient about the risk benefit ratio for SAVR versus

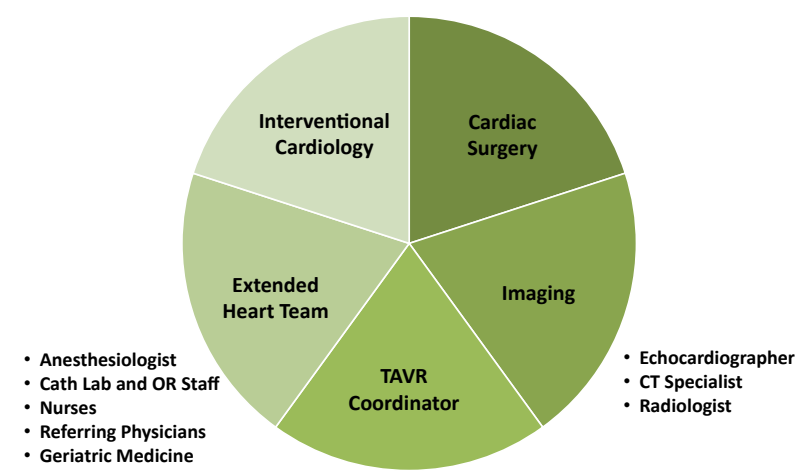

FIGURE 1. Components of the heart team. Cath Lab, Catheter laboratory; $O R$, operating room; TAVR, transcatheter aortic valve replacement; $C T$, computed tomography. 
TAVR as well as specific access routes, prosthetic type, and type of anesthesia.

4. Performance of the procedure. This will include details of the place of the procedure that is hybrid operating rooms or catheterization laboratory, types of anesthesia (general vs moderate intravenous sedation), access route (TF or non-TF), selection of device size culminating in optimizing placement of the TAVR prosthesis documenting its stable position, and hemodynamic results.

5. Periprocedural care and follow-up. In this group the Heart Team will need to include general cardiology as a bridge to the primary care giver of the patient which is essential for continuity.

The potential advantages can be seen in Table 1. These relate to patient centric care, resource use, professional satisfaction, procedural reimbursement, and generation of new knowledge in the field to optimize results in the future as well as develop new approaches to treatment.

The success with the appropriate use of the Heart Team has transformed the culture of management of AS in the United States. Patients have benefited with expeditious decision making with the comanagement of these complex patients, while maintaining equipoise regarding patient care. In contrast, some centers in Europe performed TAVR without integration of a full Heart Team, particularly in the early years of this transformative technology. The future role and preservation of the Heart Team is critical as cardiologists and cardiac surgeons should continue to maintain this check and balance system for providing optimal care not only for those with AS but in the widening field of transcatheter mitral valve technologies.

\section{UPDATES FROM THE EUROPEAN REGISTRIES German Aortic Valve Registry}

The German Aortic Valve Registry (GARY) was founded by both the German Society of Cardiology and the German
Society of Cardiothoracic and Vascular Surgery in 2010. The idea of this all-comers registry is to capture surgical and transcatheter interventions in Germany with a 5-year follow-up. Financial support was given by both societies, the German Heart Foundation, and generous support by various industry partners. Hospital outcomes were reported to the independent research institute, BQS Institute, which performs the follow-up and statistical analyses. The GARY registry was very well accepted by 90 participating German institutions, and more than 100,000 patients have agreed to participate in this unique registry. Patients collected within the GARY registry include those undergoing isolated SAVR, SAVR combined with coronary artery bypass grafting (SAVR + CABG), and TAVR with TFTAVR or transapical access (TA-TAVR). ${ }^{11,19-21}$

The first report published in the European Heart Journal by Hamm and colleagues ${ }^{19}$ demonstrated that $98.5 \%$ of the patients could be followed and hospital mortalities were depicted for SAVR, SAVR + CABG, and TAVR. In this early series the surgical results seemed to be better in all groups with low, intermediate, and greater European System for Cardiac Operative Risk Evaluation (euroSCORE) score, whereas in the highest risk scores TF-TAVR had similar outcomes. ${ }^{19}$

One of the primary aims of this database is to compare transcatheter with conventional surgical treatment. Based on the newly created German Aortic Valve Score that stratifies patients into 4 risk groups with low $(0 \%-20 \%)$, moderate $(20 \%-40 \%)$, intermediate $(40 \%-60 \%)$, and high $(<60 \%)$ risk, observed mortality is compared with expected mortality. ${ }^{11,19-21}$

Various analyses from this registry have yielded highly interesting findings. At the 1-year follow-up, patients undergoing conventional SAVR in the low-risk group demonstrated excellent results, whereas transcatheter-based therapy proved to be a very good alternative for elderly and high-risk patients. ${ }^{19,20}$ One-year survival rate was

TABLE 1. Potential outcomes of effective heart team interventions

\begin{tabular}{lcc}
\hline & Patient & Clinician \\
\hline Improved knowledge & $\mathrm{X}$ & $\mathrm{X}$ \\
Reduced decisional conflict & $\mathrm{X}$ & $\mathrm{X}$ \\
Greater satisfaction (with care delivery process) & $\mathrm{X}$ & $\mathrm{X}$ \\
Involvement in shared decision making & $\mathrm{X}$ & $\mathrm{X}$ \\
Improved QoL & $\mathrm{X}$ & $\mathrm{X}$ \\
Expanded clinical and procedural skill set & & $\mathrm{X}$ \\
Reduction in variability both in access and outcome & & $\mathrm{X}$ \\
Greater adherence to guidelines & & $\mathrm{X}$ \\
Lower readmission rates & & $\mathrm{X}$ \\
Shorter length of stay & & $\mathrm{X}$ \\
Faster time to decision & & $\mathrm{X}$ \\
Lower cost & & $\mathrm{X}$ \\
Improved care coordination and communication & & \\
\hline
\end{tabular}

QoL, Quality of life. 
$93.2 \%$ and $89.4 \%$ for the SAVR and SAVR + CABG patients, respectively. ${ }^{21}$ Furthermore and very importantly, total stroke rates were low (between $3.0 \%$ and $4.0 \%$ ) in comparison with TAVR. ${ }^{21}$ The GARY registry has disclosed good outcomes after TAVR and a survival of approximately $60 \%$ of TAVR patients who experienced severe vital complication. ${ }^{11}$ In addition, severe complications have steadily decreased over time (Figure 2).

\section{The French Registry}

With the first successful human TAVR case performed in France by Alain Cribier in 2002, ${ }^{22}$ it is only fitting that one of the earliest registries to evaluate TAVR is from France. Eltchaninoff and colleagues ${ }^{23}$ described 244 consecutive patients undergoing TAVR from February to July 2009 from 16 centers selected by the French Ministry of Health based on the presence of a multidisciplinary on-site team of an interventional cardiologist, cardiothoracic surgeon, anesthesiologist, and an imaging specialist. The French Ministry required an annual volume of $>200$ aortic valve replacement (AVR) per year, experience in balloon aortic valvuloplasty and/or TAVR, and a geographic distribution throughout the country. The registry was under the authority of the French Societies of Cardiology and Thoracic and Cardio-Vascular Surgery. A unique aspect of this registry included the evaluation of both balloon- and selfexpanding TAVR prostheses. For all patients, the Society of Thoracic Surgeons (STS) predicted risk of operative mortality was $18.9 \pm 12.8 \%$, with a mean age of 82.3 $\pm 7.3 \%$. There was a 30 -day mortality of $12.7 \%$ and an initial stroke rate of $3.6 \%$. $^{23}$

Subsequently, in January 2010, a total of 34 centers were authorized to perform TAVR by the French Ministry of Health and named the French Aortic National CoreValve and Edwards (FRANCE 2) TAVR Registry. ${ }^{24}$ Gilard and colleagues $^{24}$ evaluated 3195 patients from 2010 to 2011 with a mean age of $82.7 \pm 7.2$ years and a STS score of $14.4 \pm 11.9 \%$. They noted a remarkable $96.9 \%$ procedural success rate, as well as a $9.7 \%$ 30-day and $24.0 \% 1$-year

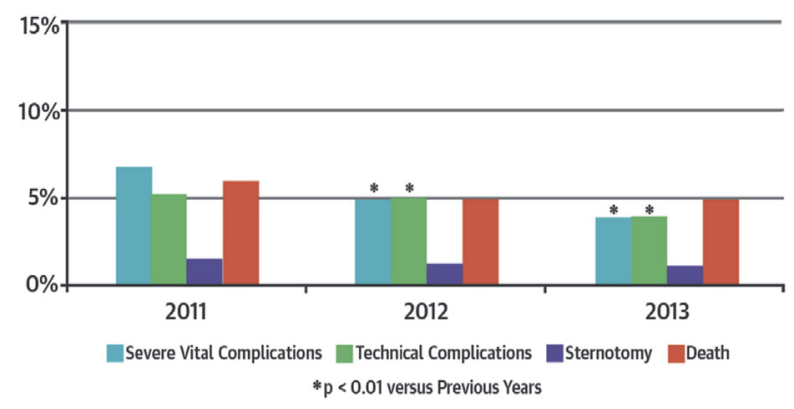

FIGURE 2. Decreasing incidence of severe transcatheter aortic valve replacement complications in Germany from 2011 to 2013 (with permission from Walther and colleagues ${ }^{11}$ ). mortality. At 30 days, there was greater mortality in those undergoing TA-TAVR compared with $\mathrm{TF}(13.9 \%$ vs $8.5 \%$ ), but no difference between the balloon- and selfexpanding valves $(9.6 \%$ vs $9.4 \%)$. The major stroke rate had decreased from previous studies to $2.3 \%$. Since the initial report from the FRANCE 2 registry, these investigators have contributed importantly to this burgeoning field with reports such as those on the predictive factors to risk assessment, ${ }^{25}$ outcomes related to pacemaker implantation, ${ }^{26}$ and prognostic value of pre-existing and new onset atrial fibrillation. $^{27,28}$

\section{The United Kingdom (U.K.) TAVR Registry}

The U.K. TAVR registry initiated in 2007 with centers performing TAVR in England and Wales. The Society of Cardiothoracic Surgery in Great Britain and Ireland and the British Cardiovascular Intervention Society established the dataset on short term outcomes, whereas longer term mortality was tracked via the National Health Service Central Registry. The initial publication from the U.K. registry by Moat and colleagues ${ }^{29}$ was unique in that it captured all 870 TAVR procedures performed in this region, with $100 \%$ follow-up, and encompassed implants from both the original SAPIEN and CoreValve devices. In a high-risk patient cohort, they noted a 30-day survival of $92.9 \%$, very similar to other national databases. The learning curve was quite dramatic, such that over a 2-year time period, the authors noted an approximately $96 \% 30$-day survival in those patients undergoing TAVR in 2009. This was also one of the first reports to evaluate patients with at least a 1-year follow-up; they noted a $78.6 \%$ and $73.7 \%, 1$ - and 2-year survival, respectively. ${ }^{29}$ In a follow-up study of the same patients, Duncan and colleagues ${ }^{30}$ reported an acceptable 3and 5-year survival rates of $61.2 \%$ and $45.5 \%$, respectively.

Since then, the U.K. TAVR registry has been very productive in evaluating all aspects of this burgeoning treatment for AS. Fröhlich and colleagues ${ }^{31}$ recently noted that TA and transaortic TAVR had similar results and were worse than those undergoing TF-TAVR. However, they also noted that mortality in those patients undergoing subclavian access was similar to TF-TAVR and may represent the safest nonfemoral access route. Most recently, Ludman and colleagues $^{32}$ evaluated $92 \%$ of all TAVR cases done in England and Wales from 2007 to 2012 with follow-up of $>6$ years. They noted that the mean age of patients remains older than 80 years of age and the logistic euroSCORE of approximately $18 \%$ has not declined during this 6-year time period. The strongest independent predictor for longterm survival was periprocedural stroke, whereas nonfemoral access and postoperative aortic regurgitation were also significant predictors. ${ }^{32}$ The authors also found a significant decrease in major preprocedural complications during the 6-year time period secondary to device iterations and physician experience. When comparing the impact of 
TAVR on SAVR volume in the United Kingdom from 2006 to 2012 , Grant and colleagues ${ }^{33}$ noted that TAVR has grown from $0.8 \%$ of all implants to $10.9 \%$ in 2012 , whereas overall TAVR and SAVR volumes also increased. They did note that, as expected, the TAVR patients were older $(81.3 \pm 7.6$ years vs $68.1 \pm 12.5$ years $)$ and had a higher mean logistic euroSCORE $(21.9 \pm 13.8 \%$ vs 7.9 $\pm 8.8 \%$ ) than those undergoing isolated SAVR. Correspondingly, they observed 30-day mortality rates of $2.1 \%$ for isolated AVR and $6.2 \%$ for TAVR, as well as 5-year survival rates of $82.6 \%$ and $46.1 \%$, respectively.

\section{The U.S. STS/American College of Cardiology Transcatheter Valve Therapies Registry}

Since its inception in January 1, 2012, virtually all patients treated with commercial TAVR devices have been enrolled at the 348 centers approved in the United States and have been entered into the Transcatheter Valve Therapies (TVT) Registry. ${ }^{12,34,35}$ By the end of 2014, 26,414 patients had been included whereas up through the end of 2015 approximately 35,000 have been so entered. In addition to these patients, approximately 5 to 10,000 additional research cases also have been performed that are not included in the TVT Registry because of industry and regulatory issues.

The latest published data document the demographics, which continue to describe the patients as elderly (mean 82 years), severely symptomatic (approximately $83 \%$ New York Heart Association [NYHA] III/IV), and with multiple comorbidities. Over the experience of the registry, the mean STS score has decreased through the end of $2014 .{ }^{12}$ For the calendar year 2014 , the median score was 6.69. This decrease has been the result of changing protocols as well as changing experience with lower risk patients. Important trends have been identified (1) the final aortic valve mean gradient is $<20 \mathrm{~mm} \mathrm{Hg}$ in $95 \%$ of patients; (2) in-hospital mortality is currently (2014) 4.4\% and device success (Valve Academic Research Consortium-1 criteria) is $93.7 \%$; (3) vascular complications continue to decrease now down to $4.2 \%$ whereas neurologic complications remain stable at $2.2 \%$; and (4) procedural performance has changed, with a marked increase in TF approach and typically now percutaneous access techniques are used. These latter trends should continue as sheath and device technology becomes smaller.

Registries such as TVT are important in that they facilitate information analysis on large groups of consecutive patients and offer the chance to identify specific factors associated with adverse outcomes, such as chronic kidney disease (CKD). Furthermore, they offer the opportunity for development of TAVR-specific risk prediction models for a variety of endpoints including in-hospital 30-day and 1 -year mortality as well as stroke. Such risk prediction models are extremely useful for patient education and selection and are forthcoming.

Such registries are also important for monitoring "realworld" outcomes and quality assessment after the approval of new devices and widespread adoption across cardiovascular centers. For example, mortality rates for TAVR observed in the TVT registry have been roughly equivalent to STS predicted risk of mortality. In contrast, device approval studies, which tend to be performed in selected centers with documented expertise, consistently reveal mortality rates that are lower than STS scores (Figure 3). Such data support the argument for centralization of TAVR in centers with volume and expertise.

\section{The Canadian Registry}

The Canadian TAVR multicenter experience evaluated the initial 339 patients who had undergone TAVR with a balloon-expandable valve (Cribier-Edwards or Edwards SAPIEN; Edwards Lifesciences, Irvine, Calif) in Canada between 2005 and 2009. The patients were treated under a special access program approved by Health Canada. This series reflects the very initial TAVR experience in Canada and provided one of the first analyses of the factors associated with poorer acute and late outcomes. ${ }^{36,37}$ The patients had a very high or prohibitive surgical risk (mean STS score of approximately $10 \%$ ) and one of the main results of the study was related to the relatively high mortality rate at 1 $(24 \%)$ and 4-year (56\%) follow-up. Late (>30-day) mortality was due to noncardiac causes in most $(60 \%)$ patients. The main predictors of poorer late outcomes were chronic obstructive pulmonary disease (COPD), CKD, frailty (as evaluated by the "eyeball test"), and chronic atrial fibrillation.

The Canadian TAVR experience evidenced the relatively high mortality rates associated with TAVR in extreme-risk patients at mid- to long-term follow-up and highlighted the importance of noncardiac comorbidities in such outcomes. Interestingly, subsequent all-comer registries with increasing centers/operators' experience and improved transcatheter valve device/delivery systems recently showed the same mortality rates $(24 \%)$ at 1 -year followup, ${ }^{24,35}$ probably reflecting the major importance of a better patient selection for improving outcomes postTAVR. The development of TAVR risks scores remains therefore of major importance for better identifying those patients likely to benefit from the procedure. Initial attempts for implementing specific TAVR risk scores have been performed within the FRANCE 2 registry for predicting 30-day mortality and the PARTNER trial for predicting 6- to 12month futile outcomes (mortality or lack of quality of life [QoL] improvement). ${ }^{25,38}$ However, no objective measures of frailty were included in such TAVR risk scores, despite that frailty increasingly has been recognized as an important prognostic factor among 


\section{TAVR vs. AVR--- STS vs Observed OM}

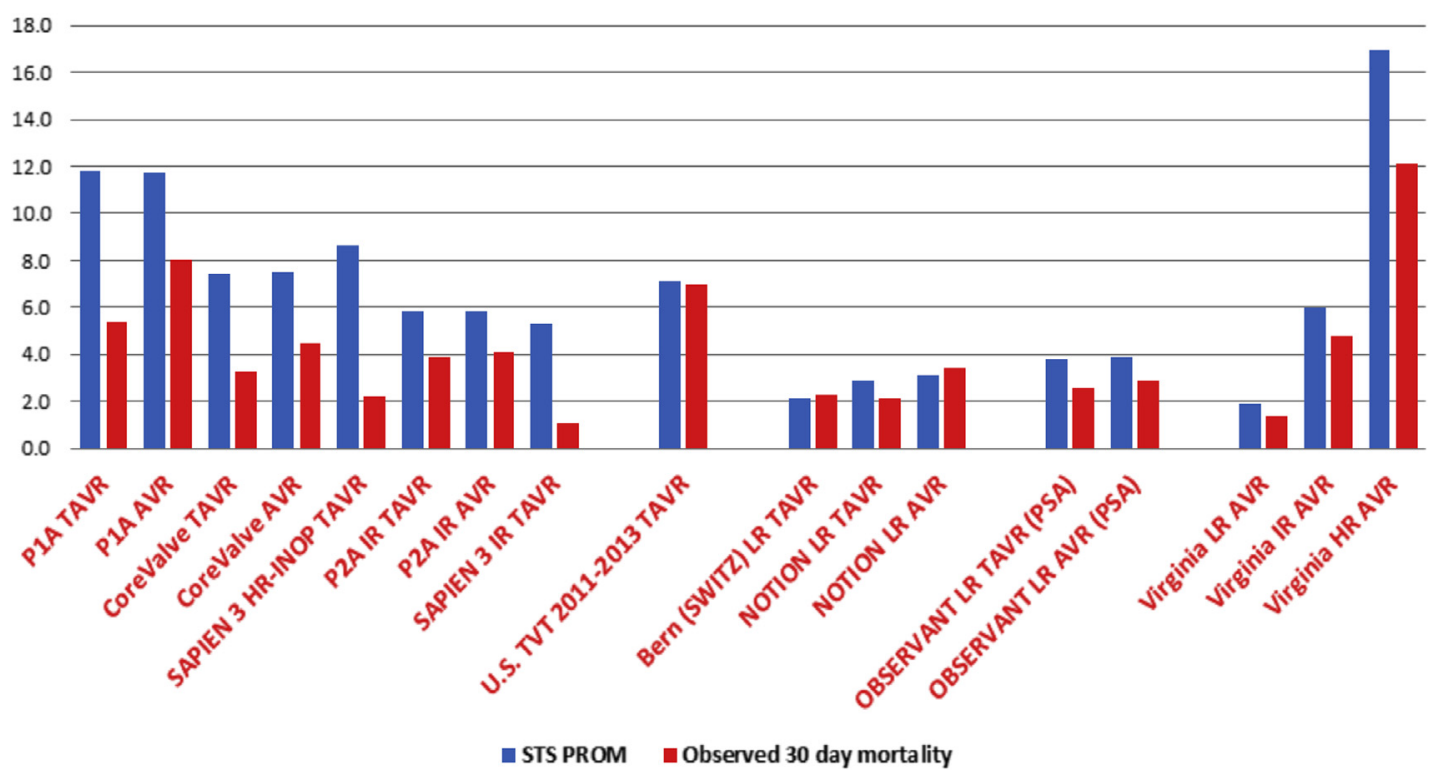

FIGURE 3. Observed versus STS predicted risk of mortality rates in TAVR registries and trials. Observed mortality rate from the TVT registry is roughly equal to STS score, whereas device approval studies tend to have lower observed mortality rates. TAVR, Transcatheter aortic valve replacement; $A V R$, aortic valve replacement; STS, Society of Thoracic Surgeons; OM, observed mortality; PROM, Predicted Risk of Mortality.

TAVR candidates. ${ }^{39}$ Further studies are warranted to further develop multivariate TAVR risk scores combining variables reflecting cardiac and noncardiac conditions and frailty.

\section{IMPACT OF INTERMEDIATE-RISK TRIALS}

As the adoption of TAVR as a treatment option in highand extreme-risk patients has grown rapidly worldwide, there remains considerable interest in expanding to a lower risk population. In a real-world U.S. experience, Holmes and colleagues ${ }^{12}$ have shown in the US TVT database that the median STS score has decreased from $7.1 \%$ in 2012 to $6.7 \%$ in $2014 .{ }^{12}$ Furthermore, they showed that $61.3 \%$ of patients in the United States had a STS score $<8 \%$ in 2014. Despite the decrease in STS score for patients undergoing TAVR in the US, there remains a paucity of data in these intermediate-risk patient populations.

Wenaweser and colleagues ${ }^{40}$ noted $16.1 \%$ 1-year allcause mortality in 254 patients with an STS score of $5.1 \%$. In several retrospective database analyses, outcomes of TAVR and SAVR patients have been compared with the use of propensity matching in intermediate-risk patients. In the Italian OBSERVANT study, Tamburino and colleagues ${ }^{41}$ compared 650 TAVR patients (mean logistic euroSCORE 2 of 5.1\%) with 650 undergoing surgery (logistic euroSCORE 2 of $4.9 \%$ ). They noted similar 1-year all-cause mortality for TAVR (13.8\%) and SAVR $(13.6 \%) .{ }^{41}$ Furthermore, they showed no difference in major adverse cardiac and cerebrovascular events between the TAVR $(18.2 \%)$ and the SAVR (17.6\%) groups. Similarly,
Piazza and colleagues ${ }^{42}$ propensity matched 810 TAVR and SAVR patients with an STS score between $3 \%$ and $8 \%$. They noted no difference in 1-year mortality between groups (TAVR: $16.5 \%$ and SAVR: $16.9 \%$ ). In lower-risk patients, the only randomized trial to compare TAVR $(\mathrm{n}=145$, mean STS score $2.9 \%)$ with surgery $(\mathrm{n}=135$, mean STS score 3.1\%) was in the all-comers NOTION trial. ${ }^{43}$ These authors showed similar rates of adverse events at 1 year with TAVR versus SAVR $(13.1 \%$ vs $16.3 \%$, $P=.43$ for the composite endpoint of death, stroke, and myocardial infarction). The authors did note a $4.9 \%$ allcause death at 1 year; however, this was not statistically different from the SAVR group $(7.5 \%, P=.38)$. It is important to note, however, that the NOTION trial was underpowered for most major outcomes.

Most recently, the PARTNER 2A randomized trial comparing TAVR and SAVR and the PARTNER 2 SAPIEN 3 intermediate-risk propensity score analysis have been published. ${ }^{13,14}$ These 2 publications evaluated more than 3000 intermediate-risk patients with severe AS. The first randomized 2032 patients to either the second-generation balloon-expandable SAPIEN XT transcatheter heart valve (THV) or SAVR. Leon and colleagues ${ }^{13}$ reported the 2-year rate of mortality or disabling stroke was similar between TAVR (19.3\%) and SAVR (21.1\%) (Figure 4). However, in the TF-TAVR cohort, TAVR resulted in a lower rate of death or disabling stroke than surgery $(P=.05)$. In the transthoracic-access cohort, outcomes were similar between groups. TAVR resulted in lower rates of acute kidney 
injury, severe bleeding, and new-onset atrial fibrillation; surgery resulted in fewer major vascular complications and less paravalvular aortic regurgitation. Some questions have been raised regarding the comparability of the 2 patient groups since concomitant procedures were more common in SAVR patients. Comparison of SAVR with TF-TAVR patients also is limited by the fact that greater risk transthoracic patients were excluded.

Kodali and colleagues ${ }^{44}$ recently described the lowest 30 day mortality in intermediate-risk patients (approximate STS score of $5 \%$ ) using the third-generation balloonexpandable SAPIEN 3 THV including a mortality incidence of $1.1 \%$, disabling strokes of $1.0 \%$, and moderate/severe paravalvular regurgitation of $3.8 \%$. A follow-up study of these SAPIEN 3 patients included a propensity score analysis by Thourani and colleagues $^{14}$ comparing 963 intermediate-risk patients undergoing TAVR with 747 SAVR patients of PARTNER 2A trial. At 1 year, these investigators showed that TAVR was superior to SAVR for the primary composite endpoint of mortality, stroke, and moderate or severe aortic regurgitation $(P<.0001)$. Moreover, they noted that for the individual endpoints of all-cause mortality and all-stroke, TAVR was superior to SAVR. However, SAVR had significantly less rates of $>$ moderate aortic regurgitation post-implant compared to TAVR, which was $1.5 \%$ at 1 year. With the data just published from these trials, some have suggested that TF-TAVR might be the preferred treatment alternative in intermediate-risk patients. Further supportive evidence may arise from the results of the SURTAVI trial investigating the CoreValve device (Medtronic, Minneapolis, Minn) in intermediate-risk patients, which are expected next year.

Currently, both the American Heart Association/American College of Cardiology and European guidelines have noted that surgical AVR is the procedure of choice for those considered intermediate risk. With recent data regarding this patient population, the guidelines committees will have an additional charge to evaluate the role of TAVR in this population, which is approximately $14 \%$ of all patients undergoing SAVR in the United States. ${ }^{7}$ Furthermore, it is important to note that improvements in preprocedural planning have led to improved TAVR outcomes and that many device-related complications of TAVR, including paravalvular leaks (PVLs) or the need for a permanent pacemaker, may become less common with later generations of devices.

One of the major issues that needs to be determined before widespread adoption of TAVR in intermediate-risk patients can be recommended is TAVR device durability. Limited data on durability currently are available because TAVR was applied initially to high-risk patients with limited survival. ${ }^{45}$ A recent presentation on early TAVR degeneration raised a lot of interest, ${ }^{46}$ but some have questioned the methodology of this study. Although longer follow-up is required to assess valve durability and risk of valve thrombosis (see LEAFLET IMMOBILITY), the movement towards TAVR

Intention-to-Treat Population

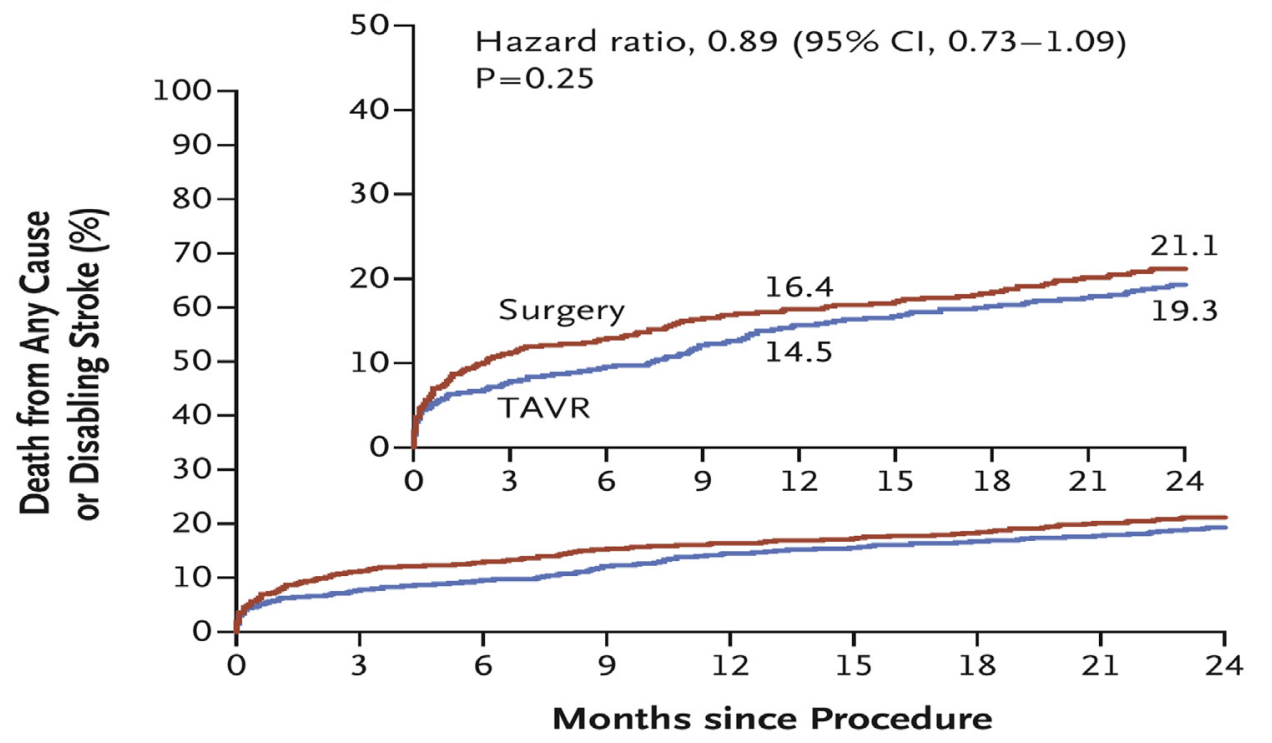

No. at Risk

$\begin{array}{llllllllll}\text { TAVR } & 1011 & 918 & 901 & 870 & 842 & 825 & 811 & 801 & 774 \\ \text { Surgery } & 1021 & 838 & 812 & 783 & 770 & 747 & 735 & 717 & 695\end{array}$

FIGURE 4. Mortality and stroke rates for surgical aortic valve replacement versus TAVR in intermediate-risk patients (with permission from Leon and colleagues $^{13}$ ). No significant difference was observed between groups. $C I$, Confidence interval; TAVR, transcatheter aortic valve replacement. 
in lower-risk patients is inevitable. Indeed, 2 randomized trials have begun in the United States that compare TAVR with SAVR in low-risk patients (ClinicalTrials.gov identifiers NCT02675114 and NCT02701283).

Patterns in financial reimbursement may affect the number of TAVR procedures that are currently performed, particularly in Europe. The current reimbursement system allows for liberal use of TAVR in Switzerland, Denmark, and Germany, whereas financial restrictions are quite marked in other European countries (eg, Spain, Portugal, United Kingdom) ${ }^{47,48}$ The number of TAVR might increase in these countries if the financial restrictions disappeared. In addition, the number of open heart surgery per million inhabitants in southern Europe is much less than in the United States and Northern Europe. ${ }^{49}$ The difference may be the result of differences in financial remuneration or a difference in the incidence of aortic valve disease.

\section{SPECIFIC PATIENT CHARACTERISTICS}

The advent of TAVR spawned effective treatment of patients with symptoms due to severe AS who otherwise could not or would not be offered SAVR. The evolution of the field started with randomized, controlled trials of TAVR compared with standard medical therapy in inoperable patients (PARTNER 1B and CoreValve extreme risk trials) and moved to comparison of TAVR with conventional SAVR in high surgical risk patients (PARTNER 1A and CoreValve Pivotal trials). Consequently, 2 of 3 prospective studies studying intermediate-risk AS patients (PARTNER P2A, PARTNER S3i, and SURTAVI trials) recently have been published in the US. ${ }^{13,14}$ As expected and secondary to a multitude of reasons, notably better patient selection, the risk of TAVR has declined over time.

It must be remembered that coexistent diseases such as end-stage renal disease (ESRD) requiring renal replacement, recent stroke, untreated coronary artery disease, poor left ventricular (LV) systolic function (left ventricular ejection fraction $[\mathrm{LVEF}]<30 \%$ ), severe chronic COPD, severe pulmonary hypertension, severe mitral regurgitation (MR), active neoplasms, and endocarditis were generally exclusion criteria in the aforementioned clinical trials. Other factors, such as frailty, dementia, active cancer, debilitating frailty, and liver disease, were not incorporated into the overall risk assessment process in the early trials. These patients, commonly called "Cohort C," remain a difficult cohort in terms of determining the most appropriate therapy.

Even though these sicker patients were excluded, the allcause 5 year mortality rates of patients who received TAVR in the PARTNER 1B and 1A trials were $72 \%{ }^{8}$ and $68 \%,{ }^{9}$ respectively. These very high attrition rates reflected how old and sick these selected individuals were. Indeed, investigation of overall poor outcome (combined lack of functional benefit, poor QoL, and death) by Arnold and colleagues $^{38}$ were eye opening in showing that one third of 2137 patients in the PARTNER-1 trial population had a poor outcome by 6 months. Real-world application of TAVR is not constrained by the strict exclusion criteria inherent in the controlled trials; therefore, it became important to assess overall patient outcome after TAVR. Arnold and colleagues ${ }^{50}$ analyzed survival after TAVR in 7769 patients in the U.S. TVT Registry population using preoperative patient-reported health status (assessed by the Kansas City Cardiomyopathy Questionnaire [KCCQ]) and observed that those with a KCCQ score $<25$ (very poor health status) had a 1-year mortality exceeding $25 \%$, compared with approximately $11 \%$ for those with a KCCQ score $>75$ (indicative of "good" health status).

It is essential for astute and responsible clinicians to differentiate between interventions that are very high risk and those that are futile. It generally is well accepted that SAVR or TAVR in those with an estimated life expectancy less than 1 year or in whom other diseases and disabilities realistically preclude any benefit in terms of survival, functional improvement, symptom relief, and overall QoL should not undergo the procedure. In these scenarios, physicians should provide appropriate counsel on need for a temporizing balloon aortic valvuloplasty or continuation of medical therapy. ${ }^{51-56}$

Several specific diseases or conditions portend markedly limited life expectancy and much lower likelihood of functional benefit after SAVR or TAVR and must be considered by the Heart Team in their assessment. Among these will be discussed in more detail include ESRD, ${ }^{12,35,57-61}$ advanced lung disease (especially if oxygen dependent), ${ }^{62-64}$ disability or slow ambulation (6-min walk time $<150 \mathrm{~m}$ ), ${ }^{54}$ and STS Predicted Risk of Mortality (PROM) score $>15 \%$.

\section{CKD AND ESRD}

Thirty-day mortality in those with moderate CKD or on renal replacement has been acceptable with TAVR. Nguyen and colleagues ${ }^{61}$ noted a $4.4 \%$ early mortality (STS PROM of $21 \%$ ) in patients with ESRD with severe AS and a 2.9\% in those with moderate CKD (STS PROM 13.4\%). However, 1-year mortality has been less favorable. Commercial TAVR in patients with stage 4 or 5 ESRD has been associated with 1-year mortality rates approaching $40 \%$ to $50 \%{ }^{57}$ Similarly, Mack and colleagues ${ }^{66}$ analyzed outcomes in 528 TAVR patients in the U.S. TVT Registry and observed a 1 -year mortality rate of $46 \%$ for those on dialysis. The mortality rate was $35 \%$ for those with a creatinine $>2 \mathrm{mg} / \mathrm{dL}$ but not on preoperative dialysis versus $25 \%$ for patients with a creatinine $<2.0 \mathrm{mg} / \mathrm{dL}$. In the first 2 years of the U.S. TVT Registry (2011-2013), Holmes and colleagues ${ }^{35}$ observed that dialysis-dependent TAVR patients with an STS score $\geq 15 \%$ had a 1-year mortality rate of $54 \%$, a situation in which procedural denial would have been the appropriate decision, not offering TAVR. ${ }^{35}$ In the 
UK TAVI registry between 2007 and 2012, Ferro and colleagues ${ }^{58}$ observed that an estimated glomerular filtration rate $<45 \mathrm{~mL} / \mathrm{min} / 1.72 \mathrm{~m}^{2}$ significantly increased cumulative mortality over a median interval of 543 days. This adverse impact was seen in patients with CKD stages 3, 4, and 5 and ESRD, but the predictive power of this variable was weak. ${ }^{58}$ Gargiulo and colleagues ${ }^{59}$ performed a metaanalysis including 4992 patients undergoing TAVR from 9 studies that showed that CKD stage 3-5 and ESRD increased 1-year mortality as well as early complications. Finally, Kobrin and colleagues ${ }^{60}$ examined 37,639 U.S Medicare patients and identified 194 on dialysis who underwent surgical AVR and 224 who had TAVR in 2011-2012. The dialysis-dependent TAVR patients had a $43 \%$ mortality rate at 1 year, compared with $23 \%$ for those not on dialysis $(P<.01)$. Using propensity score analysis, they identified 194 matched-pairs of patients on dialysis undergoing AVR or TAVR; 1-year mortality was almost identical (37\% for AVR vs $40 \%$ for TAVR). These inordinately high 1-year mortality rates mandate that the Heart Team should carefully weigh all options in these patients and to present the patient and family with realistic expectations. Currently, there are no recommendations from either guideline on the appropriate management of patients with ESRD.

\section{CHRONIC OBSTRUCTIVE PULMONARY DISEASE}

COPD is a common comorbidity in patients presenting for TAVR. Mok and colleagues ${ }^{62}$ at Laval University in Quebec City analyzed 319 TAVR patients with respect to the combined end point of death and lack of functional benefit (improved NYHA functional class); 30\% $(\mathrm{n}=94)$ had COPD by STS definitions. The patients with COPD had a 1-year survival rate of only $71 \%$ compared with $85 \%$ for those without $\operatorname{COPD}(P=.008)$ and also attained less improvement in NYHA functional class. Of those with COPD, a shorter 6-min walk test distance significantly predicted greater cumulative mortality. An analysis of the US TVT registry of 11,656 TAVR patients by Suri and colleagues $^{64}$ showed that moderate to severe COPD was present in approximately $28 \%$ of all patients. As expected, they showed that there was a greater 1-year mortality in those with moderate $(25.5 \%)$ and severe COPD $(32.3 \%)$ compared with no or mild COPD $(8 \%)$. Of those with COPD, the 1-year mortality rate was highest in those with severe pulmonary hypertension (right ventricular systolic pressure $>55 \mathrm{~mm} \mathrm{Hg}$ ) or requiring home oxygen use ( $36 \%$ and $35 \%$, respectively). For this analysis, postoperative health status and QoL data were not available. ${ }^{64}$ In a series of patients with pre- and postoperative pulmonary function testing, Gilmore and colleagues ${ }^{63}$ showed that after TAVR an improvement in at least one COPD grade was evident in $64 \%$ of moderate and $50 \%$ of severe COPD patients. Furthermore, in those with severe COPD and concomitant AS, some have advocated for an initial balloon aortic valvuloplasty to assess improvements in symptoms. If the symptoms are ameliorated, then the TAVR is performed, but if not, then no further interventional treatment has been recommended. Currently, there are no recommendations from either guideline on the appropriate management of patients with severe COPD.

\section{STS PROM (PREDICTED OPERATIVE MORTALITY) SCORE}

Even though the STS risk algorithm was developed with the use of early (30-day) death after open surgical AVR as the dependent variable, it was convenient to use this risk score for patient selection in the early controlled TAVR trials. In the PARTNER 1B trial despite an overall approximately $20 \%$ improvement in late survival rate compared with standard therapy, patients receiving TAVR with an STS score over $15 \%$ did not have any appreciable benefit in terms of all-cause mortality out to 5 years $(P=.075) .{ }^{8}$ It was only with respect to cardiovascular death at the 5-year mark was TAVR in patients with an STS score $>15 \%$ significantly better than medical therapy $(P=.01){ }^{8}$ Therefore, when the STS score exceeds $15 \%$, a careful assessment with the Heart Team is valuable in deciding if TAVR is a futile or viable option.

\section{FRAILTY, COGNITION, QoL, IMMOBILITY, AND DISABILITY}

Arnold and colleagues ${ }^{67}$ using PARTNER Trial TAVR patients, were the first to compile an analytic risk predictor based on the KCCQ. Poor outcome was defined as death, KCCQ $<45$ or decrease in KCCQ $\geq 10$. Thirty-five percent of patients had a poor outcome at 6 months $(19 \%$ dead, $16 \%$ alive without functional benefit). ${ }^{67}$ Looking at 1 -year outcome after TAVR in 3 PARTNER sites where frailty was rigorously assessed this group used a KCCQ threshold of $<60$ to define poor outcome. ${ }^{52}$ The frail patients had a $33 \%$ mortality rate compared with $16 \%$ for those not deemed frail $(P=.004)$; poor outcome occurred in $50 \%$ of the frail subgroup versus $32 \%$ of the nonfrail subgroup $(P=.02) .{ }^{52}$

When the 2011-2014 U.S. TVT Registry cohort was analyzed using baseline and 1-year KCCQ, those who initially self-reported very poor health status $(\mathrm{KCCQ}<25)$ had a 1 -year mortality exceeding $25 \%$ after TAVR, more than twice as high as those who felt they had "good" health status at baseline. ${ }^{50}$ Puls and colleagues ${ }^{68}$ observed that frailty as assessed by the simple Katz index of daily living activities had a major influence on TAVR outcome in a German single center study. Adjusted for all other variables, patients with a Katz score $<6$ had a $47 \%$ mortality rate at 2 years compared with $26 \%$ for those with a Katz index $=6$, with an intermediate outcome for those with a Katz index 3-5. Approximately $50 \%$ of patients with a Katz index $\leq 2$ were dead by 2 years. ${ }^{68}$ There remains considerable research required to ascertain the differentiation of frailty as an 
exclusion for those undergoing TAVR. Although the guidelines only currently note that those patients who have a survival less than 1 year should not be candidates for TAVR, more guidance to physicians in this aspect is warranted.

Aside from identifying patient characteristics portending high mortality over the first few years after TAVR, an equally important consideration is avoiding this procedure in patients who realistically will not gain any functional benefit or have better QoL. ${ }^{56}$ Schoenenberger and colleagues ${ }^{69}$ found that $21 \%$ of 106 surviving TAVR patients at 6 months had actually suffered functional decline. Using a multidisciplinary frailty index (cognition, mobility, nutrition, activities of daily living) they demonstrated that this frailty index strongly predicted functional decline, even when adjusted for STS and euroSCORE. Such measures should be incorporated in the TAVR triage process along with active gerontology and palliative care representation on the Heart Team to avoid a procedure in patients who are not going to benefit from TAVR. ${ }^{56}$

\section{DEPRESSED EF}

The prevalence of depressed LVEF in TAVR candidates ranges between approximately $10 \%$ and approximately $30 \%{ }^{70}$ The association between depressed LVEF and clinical outcomes post-TAVR is controversial. Whereas some studies have shown an association between low LVEF and poor outcomes, ${ }^{71-73}$ others such as the PARTNER trial ${ }^{74}$ failed to demonstrate such an association. Differences in inclusion criteria and the cut-offs used for defining low LVEF may partially explain such differences.

Emerging evidence suggests that LVEF itself may not accurately represent the true extent of myocardial dysfunction in the setting of severe AS. Rather, reduced transaortic flow may be a more important prognostic factor. Thus, several studies have identified a lower transvalvular gradient preprocedure as an important marker of poor outcomes post-TAVR. ${ }^{38,75,76}$ More recently, a low-flow state (defined as stroke volume index $\leq 35 \mathrm{~mL} / \mathrm{m}^{2}$ ) has been associated independently with a greater rate of mortality after TAVR irrespective of LVEF. ${ }^{77,78}$ In those patients with low LVEF and a low transvalvular gradient (ie, LVEF $\leq 40 \%$, aortic valve area $\leq 1.0 \mathrm{~cm}^{2}$, and transvalvular gradient $<40 \mathrm{~mm} \mathrm{Hg}$ ), it remains very important to assess the presence/absence of contractile reserve as a means of further risk-stratification. ${ }^{15}$ This usually requires dobutamine stress echocardiography to assess for an augmentation in stroke volume (of $\geq 20 \%$ ), indicative of the presence of contractile reserve. ${ }^{79}$ Further insights into these issues will come from the ongoing TOPAS registry (NCT01835028), which is evaluating clinical outcomes and prognostic markers in patients with low-flow, lowgradient AS. This registry will include a significant proportion of patients treated with TAVR (ie, the TOPAS-TAVR cohort).
Pulmonary hypertension and MR are frequent features in patients with AS and low LVEF. Severe pulmonary hypertension, particularly precapillary or combined, has been associated with a greater mortality post-TAVR ${ }^{55}$ The presence of severe MR also has been associated with a higher 30-day and 1-year mortality post-TAVR. Although severe functional MR may partially recover post-TAVR, organic $\mathrm{MR}$, which is not uncommon in elderly patients, is unlikely to improve post-TAVR. ${ }^{80}$

In summary, available data suggest that low LVEF cannot be used as an isolated factor for determining poor outcomes post-TAVR. Rather, the presence of a low-flow state, lack of contractile reserve, severe pulmonary hypertension, and severe MR are factors that should be considered in the clinical decision-making process of TAVR candidates with low LVEF.

\section{PATIENTS WITH FAILED SURGICAL BIOPROSTHESIS}

With the rapid adoption of TAVR to treat native AS, significant technical experience and familiarity with these procedures has accumulated, prompting clinicians to use transcatheter valve technology to treat patients with other forms of valvular heart disease. An increasingly common scenario is a patient who presents with prosthetic valve dysfunction after previous SAVR. Although initial case reports were published nearly a decade ago, ${ }^{81}$ increasing amounts of data are now emerging that support the use of this technology to treat prosthetic valve dysfunction for degenerated surgical valves, particularly when situated in the aortic position.

The largest data set of transcatheter aortic valve-in-valve replacement (ViV-TAVR) resides within the VIVID registry with recently published 1 year results for the CoreValve and SAPIEN devices. ${ }^{82,83}$ In comparison with patients with native AS treated with TAVR, patients undergoing ViVTAVR have demonstrated lower rates of PVL and are less likely to require permanent pacemaker implantation after the procedure. ${ }^{84}$ As the anatomy of the surgically altered aortic root can be distorted and more rigid, however, THV malposition and coronary obstruction occur more frequently during ViV-TAVR procedures at rates of $15 \%$ and $3.5 \%$, respectively. ${ }^{83}$ THV malpositioning often results in the need for a second THV implant but may result in fatality in the case of coronary obstruction. The overall survival among patients within the VIVID registry was $83 \%$ at 1 year. Given that only high-risk patients were enrolled, these results are quite encouraging, particularly given that surviving patients reported overwhelming NYHA class I or II symptoms at 1-year follow-up. ${ }^{82}$

The registry has identified a subgroup of patients, however, that have elevated postprocedural aortic valve gradients and subsequent worse outcomes at 1 year. Although mildly elevated gradients after ViV-TAVR are to be expected when 
compared with traditional TAVR, nearly $30 \%$ of patients within the VIVID registry demonstrated mean aortic gradients $\geq 20 \mathrm{~mm} \mathrm{Hg}$. This occurred most frequently among patients in whom a THV implant was placed within a smaller surgical valve (ie, $<23 \mathrm{~mm}$ labeled size).

To avoid intraprocedural complications and achieve optimal results with ViV-TAVR, the following practical recommendations for patient workup and procedure are suggested:

1. Perform a thorough assessment of the degenerated bioprosthetic surgical valve:

a. Identify the mechanism of prosthetic valve dysfunction (stenosis, regurgitation, mixed).

b. Determine the model type and size of prosthesis implanted.

c. Understand the fluoroscopic appearance of the surgically implanted valve.

d. Evaluate for the presence of patient prosthesis mismatch or PVL, both contraindications to ViVTAVR.

2. Assessment of the patient aortic root anatomy:

a. Presence of patent bypass grafts.

b. Height of coronary ostia.

c. Width of coronary sinuses and height of the sinotubular junction.

d. Degree of aortic root calcification.

Previous echo reports may be helpful to demonstrate previous normal prosthetic valve function. The surgical operative note should be obtained to identify the type and size of the implanted valve, as well as any comments regarding unusual aortic root anatomy (ie, aberrant coronary ostia). Although CT scanning is required to help with THV sizing and access route planning, coronary anatomy, valve leaflet mobility and presence of pre-existing PVL can often only be fully delineated by angiography and transesophageal echocardiography. ${ }^{84,85}$

In addition to the aforementioned contraindications, patients with stented bioprosthetic valves either with bulky leaflet calcification or with externally mounted leaflets (Mitroflow, Sorin, and Trifecta; St Jude, St Paul, Minn) are more prone to develop coronary obstruction particularly in patients with low coronary heights, narrow sinuses, or with a short and calcified sinotubular junction. Surgical valves without a clear, radiopaque fluoroscopic footprint (ie, stentless valves), particularly in the setting of severe aortic insufficiency, lend themselves to anatomic misrecognition and device malpositioning.

Given appropriate patient selection, annular size is a critical determinant of procedural success and must be meticulously measured incorporating manufacturer's specifications, transesophageal echocardiography (TEE), and
CT-derived measurements. Oversized valves are likely to remain underexpanded and with elevated gradients and reduced durability whereas undersized valves more prone to PVL and device malposition. Once sized appropriately, the art of ViV-TAVR procedural planning is primarily a function of choosing the specific THV prosthesis and the identifying the optimal depth of implant within the degenerated surgical prosthesis. For now, experience with ViV-TAVR procedures has been limited primarily to CoreValve and SAPIEN devices, but case reports with DirectFlow, Portico, and Lotus valves in ViV-TAVR procedures already have been published. ${ }^{86-88}$ Although early data suggest that selfexpanding valves, particularly when implanted at a shallow depth $(<6 \mathrm{~mm})$, may have improved hemodynamic performance within a smaller surgical implant, results remain variable. Moreover, newer repositionable THV prostheses may result in a lower frequency of malpositioning and coronary obstruction. $^{88}$

ViV-TAVR is a challenging procedure because of the significant variability that exists in the interaction between surgical prosthesis, patient anatomy and the THV implant. Given the variability intrinsic to each ViV-TAVR procedure, procedural experience is effectively limited at any one given center. ViV-TAVR procedures should continue to be followed within a dedicated registry to improve education, training of implanters and awareness of outcomes for these complex procedures.

\section{LEAFLET IMMOBILITY}

SAVR continues to evolve with a progressive increase in the use of biomechanical prosthesis. This trend has been the result of improved biomechanical prosthetic durability and the ability to avoid systemic anticoagulation. Dysfunction of these specific devices, although infrequent, can result in substantial mortality and morbidity with need for repeat SAVR or prolonged anticoagulation. Recently concern has been raised about transcatheter aortic valves. This has been termed "leaflet immobility" and been highlighted in several recent series wherein valve leaflet abnormalities were identified within 1 year after implantation (Figure 5) ${ }^{89}$ Most of the information available has been based on results of 4-dimensional CT imaging studies, although this abnormality also has been documented with TEE. It has been demonstrated with multiple different devices, both commercially approved as well as research devices.

The frequency of this abnormality has varied substantially from $10 \%$ to $45 \% .{ }^{89}$ Much remains unknown about it, including, among other things: (1) What is the true incidence, it is device specific, and what are the factors associated with it? (2) Is there a clinically significant corollary associated with it? At the present time, clinical event rates are low despite the very wide demonstrated incidence. (3) 
What strategies are optimal to either prevent the abnormality or to treat it after documentation? (4) What are the optimal strategies for detection (eg, 4-dimensional CT, transthoracic echocardiography, TTE) as well as the need for routine screening and the timing of that screening?

The outcome of scientific data on these issues has important implications for the continued growth of the field. Current trials with a variety of devices and various anticoagulation strategies have been planned to address these multiple issues.

\section{FINAL THOUGHTS}

Management of patients with severe AS has undergone a profound change over the last decade due to the introduction of TAVR as disruptive technology. In addition, TAVR continues to undergo rapid evolution with regards to device technology, outcomes, and patient selection at a pace that has not been observed previously in the field of valvular heart disease. Several important studies have been published recently that will have effects on the next iteration of valvular disease guidelines. Indeed, the introduction of transcatheter therapy to the management of patients with structural heart valve disease may require more frequent updates of these guideline documents.

Initial marked differences in transatlantic clinical practice patterns for TAVR have become much less pronounced in the last couple of years. Increased use of TAVR and a shift towards nonhigh-risk patients has been observed recently in the United States after several years of such practice in $\mathrm{Eu}-$ ropean centers. Continued transatlantic communication and cooperation remains vital to further advancement in this field. Indeed, several global trials and registries already have been instigated and should be further encouraged to better define short- and long-term TAVR outcomes, risk stratification, and possible new areas of research.

One of the largest contributions of TAVR to the field of aortic valve disease is the introduction of the concept of the Heart Team, which has now been successfully applied to other areas of cardiovascular disease. Extensive cooperation between cardiology and cardiac surgery has contributed to improved outcomes for patients undergoing TAVR and the introduction of large-scale randomized trials for patients with AS, to name but a few benefits. Continued close cooperation between these and other specialties is
A

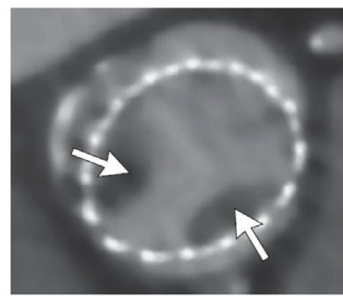

D

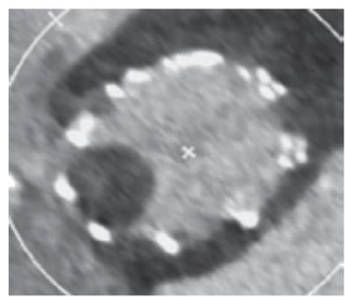

G

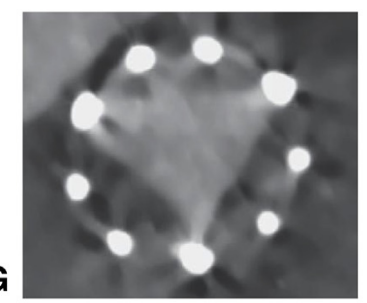

$\mathbf{J}$

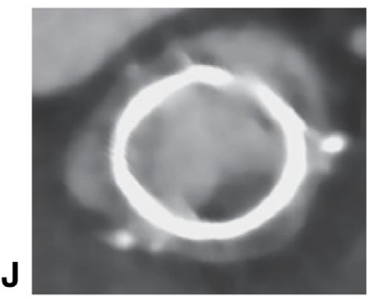

H
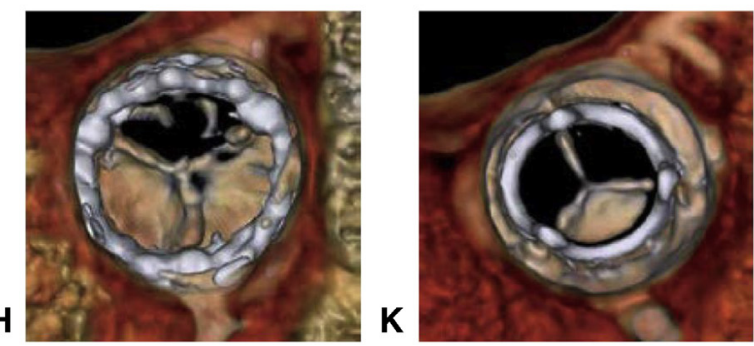

E
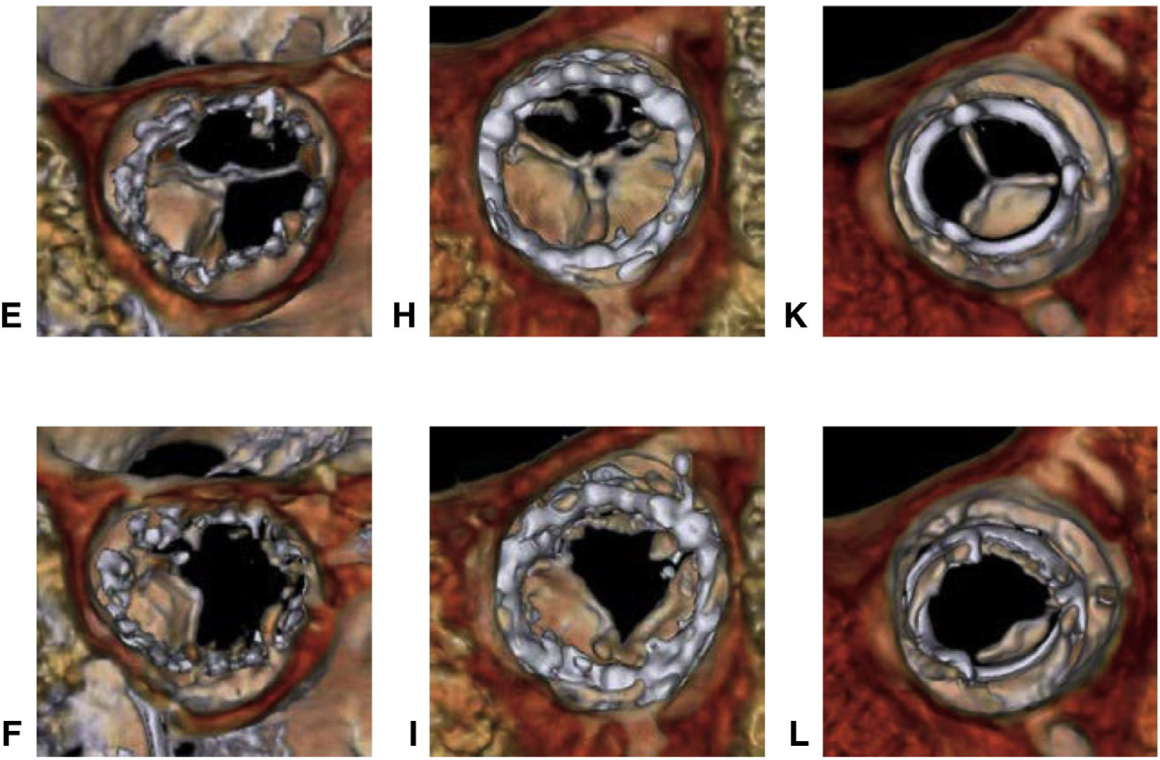

FIGURE 5. Leaflet thrombosis demonstrated by transesophageal echocardiography and 4-dimensional CT in patients with CoreValve, Medtronic (A-C), SAPIEN XT, Edwards Lifesciences (D-F), Portico, St Jude, (G-I), and Carpentier Edwards PERIMOUNT, Edwards Lifesciences (J-L) prostheses (with permission from Makkar and colleagues ${ }^{89}$ ). 
recommended for continued development and assessment of the rapidly changing area of TAVR.

\section{Conflict of Interest Statement}

Dr Thourani reports received consulting fees from Edwards Lifesciences and Abbott Vascular. Dr Borger reports lecture fees from Edwards, St Jude Medical, Medtronic, and CryoLife. He also receives consulting fees from Edwards and CryoLife. Dr Maniar reports that he is a consultant for nContact Surgical and Estech. Dr Miller reports that he has received consulting fees from Abbott Vascular, St Jude Medical, and Medtronic, in addition to being an unpaid member of the Executive Committee of the PARTNER trial. Dr Rodés-Cabau reports that he has received research grants from Edwards Lifesciences, Keystone, Medtronic, and St Jude Medical. Dr Schröfel reports that he is a proctor and consultant for Edwards Lifesciences. Mr Moat reports that he is a proctor and consultant for Medtronic. All other authors have nothing to disclose with regard to commercial support.

\section{References}

1. Go AS, Go AS, Mozaffarian D, Roger VL, Benjamin EJ, Berry JD, et al. Heart disease and stroke statistics - 2014 update: a report from the American Heart Association. Circulation. 2014;129:e28-292.

2. Ortman JMO, Guarneri CE. United States Population Projections: 2000 to 2050. Available at: http://www.census.gov/population/projections/files/analyticaldocument09.pdf. Accessed May 14, 2012.

3. Thourani VH, Myung R, Kilgo P, Thompson K, Puskas JD, Lattouf OM, et al. Long-term outcomes after isolated aortic valve replacement in octogenarians: a modern perspective. Ann Thorac Surg. 2008;86:1458-64.

4. Grossi EA, Schwartz CF, Yu PJ, Jorde UP, Crooke GA, Grau JB, et al. High-risk aortic valve replacement: are the outcomes as bad as predicted? Ann Thorac Surg. 2008;85:102-6.

5. Brennan JM, Edwards FH, Zhao Y, O'Brien SM, Douglas PS, Peterson ED, et al. Long-term survival after aortic valve replacement among high-risk elderly patients in the United States: insights from the Society of Thoracic Surgeons Adult Cardiac Surgery Database, 1991 to 2007. Circulation. 2012;126:1621-9.

6. Iung B, Cachier A, Baron G, Messika-Zeitoun D, Delahaye F, Tornos P, et al. Decision-making in elderly patients with severe aortic stenosis: why are so many denied surgery? Eur Heart J. 2005;26:2714-20.

7. Thourani VH, Suri RM, Gunter RL, Sheng S, O’Brien SM, Ailawadi G, et al. Contemporary real-world outcomes of surgical aortic valve replacement in 141,905 low-risk, intermediate-risk, and high-risk patients. Ann Thorac Surg. 2015;99:55-61.

8. Kapadia SR, Leon MB, Makkar RR, Tuzcu EM, Svensson LG, Kodali S, et al. 5 -year outcomes of transcatheter aortic valve replacement compared with standard treatment for patients with inoperable aortic stenosis (PARTNER 1): A randomised controlled trial. Lancet. 2015;385:2485-91.

9. Mack MJ, Leon MB, Smith CR, Miller DC, Moses JW, Tuzcu EM, et al. 5-year outcomes of transcatheter aortic valve replacement or surgical aortic valve replacement for high surgical risk patients with aortic stenosis (PARTNER 1): a randomised controlled trial. Lancet. 2015;385:2477-84.

10. Reardon MJ, Adams DH, Kleiman NS, Yakubov SJ, Coselli JS, Deeb GM, et al. 2-year outcomes in patients undergoing surgical or self-expanding transcatheter aortic valve replacement. J Am Coll Cardiol. 2015;66:113-21.

11. Walther T, Hamm CW, Schuler G, Berkowitsch A, Kötting J, Mangner N, et al. Perioperative results and complications in 15,964 transcatheter aortic valve replacements, prospective data from the GARY Registry. J Am Coll Cardiol. 2015;65:2173-80.

12. Holmes DR Jr, Nishimura RA, Grover FL, Brindis RG, Carroll JD, Edwards FH, et al. Annual outcomes with transcatheter valve therapy: from the STS/ACC TVT Registry. J Am Coll Cardiol. 2015;66:2813-23.
13. Leon MB, Smith CR, Mack MJ, Makkar RR, Svensson LG, Kodali SK, et al Transcatheter or surgical aortic-valve replacement in intermediate-risk patients N Engl J Med. 2016;374:1609-20.

14. Thourani VH, Kodali S, Makkar RR, Herrmann HC, Williams M, Babaliaros V, et al. Transcatheter aortic valve replacement versus surgical valve replacement in intermediate-risk patients: a propensity score analysis. Lancet. 2016;387: 2218-25.

15. Vahanian A, Alfieri O, Andreotti F, Antunes MJ, Barón-Esquivias G Baumgartner H, et al. Guidelines on the management of valvular heart disease (version 2012): the Joint Task Force on the Management of Valvular Heart Disease of the European Society of Cardiology (ESC) and the European Association for Cardio-Thoracic Surgery (EACTS). Eur J Cardiothorac Surg. 2012;42: S1-44.

16. Kochman J, Rymuza B, Huczek Z. Transcatheter aortic valve replacement in bicuspid aortic valve disease. Curr Opinion Cardiol. 2015;30:594-602.

17. Penkalla A, Pasic M, Drews T, Buz S, Dreysse S, Kukucka M, et al. Transcatheter aortic valve implantation combined with elective coronary artery stenting: a simultaneous approach. Eur J Cardiothorac Surg. 2015;47:1083-9.

18. Nishimura RA, Otto CM, Bonow RO, Carabello BA, Erwin JP III, Guyton RA, et al. 2014 AHA/ACC guideline for the management of patients with valvular heart disease: a report of the American College of Cardiology/American Heart Association Task Force on Practice Guidelines. J Thorac Cardiovasc Surg. 2014;148:e1-132.

19. Hamm CW, Möllmann H, Holzhey D, Beckmann A, Veit C, Figulla HR, et al The German Aortic Valve Registry (GARY): in-hospital outcome. Eur Heart J. 2014;35:1588-98

20. Mohr FW, Holzhey D, Möllmann H, Beckmann A, Veit C, Figulla HR, et al. The German Aortic Valve Registry: 1-year results from 13680 patients with aortic valve disease. Eur J Cardiothorac Surg. 2014;46:808-16.

21. Holzhey D, Mohr FW, Walther T, Möllmann H, Beckmann A, Kötting J, et al Current results of surgical aortic valve replacement: insights from the German Aortic Valve Registry. Ann Thorac Surg. 2016;101:658-66.

22. Cribier A, Eltchaninoff H, Bash A, Borenstein N, Tron C, Bauer F, et al. Percutaneous transcatheter implantation of an aortic valve prosthesis for calcific aortic stenosis: first human case description. Circulation. 2002;106:3006-8.

23. Eltchaninoff H, Prat A, Gilard M, Leguerrier A, Blanchard D, Fournial G, et al Transcatheter aortic valve implantation: early results of the FRANCE (FRench Aortic National CoreValve and Edwards) registry. Eur Heart J. 2011;32:191-7.

24. Gilard M, Eltchaninoff H, Iung B, Donzeau-Gouge P, Chevreul K, Fajadet J, et al Registry of transcatheter aortic-valve implantation in high-risk patients. $N$ Engl J Med. 2012;366:1705-15.

25. Iung B, Laouénan C, Himbert D, Eltchaninoff H, Chevreul K, Donzeau-Gouge P et al. Predictive factors of early mortality after transcatheter aortic valve implantation: individual risk assessment using a simple score. Heart. 2014;100 1016-23.

26. Mouillet G, Lellouche N, Yamamoto M, Oguri A, Dubois-Rande JL, Van Belle E et al. Outcomes following pacemaker implantation after transcatheter aortic valve implantation with CoreValve( $($ B) devices: results from the FRANCE 2 Registry. Catheter Cardiovasc Interv. 2015;86:E158-66.

27. Chopard R, Teiger E, Meneveau N, Chocron S, Gilard M, Laskar M, et al Baseline Characteristics and Prognostic Implications of Pre-Existing and New-Onset Atrial Fibrillation After Transcatheter Aortic Valve Implantation: results From the FRANCE-2 Registry. JACC Cardiovasc Interv. 2015;8: 1346-55.

28. Furuta A, Lellouche N, Mouillet G, Dhanjal T, Gilard M, Laskar M, et al Prognostic value of new onset atrial fibrillation after transcatheter aortic valve implantation: A FRANCE 2 registry substudy. Int J Cardiol. 2016; 210:72-9.

29. Moat NE, Ludman P, de Belder MA, Bridgewater B, Cunningham AD Young $\mathrm{CP}$, et al. Long-term outcomes after transcatheter aortic valve implantation in high-risk patients with severe aortic stenosis. The U.K. TAVI (United Kingdom Transcatheter Aortic Valve Implantation) Registry. J Am Coll Cardiol. 2011;58:2130-8.

30. Duncan A, Ludman P, Banya W, Cunningham D, Marlee D, Davies S, et al. Longterm outcomes after transcatheter aortic valve replacement in high-risk patient with severe aortic stenosis: the U.K. transcatheter aortic valve implantation registry. JACC Cardiovasc Interv. 2015;8:645-53.

31. Fröhlich GM, Baxter PD, Malkin CJ, Scott DJ, Moat NE, Hildick-Smith D, et al Comparative survival after transapical, direct aortic, and subclavian transcatheter aortic valve implantation (data from the UK TAVI registry). Am J Cardiol. 2015; 116:1555-9. 
32. Ludman PF, Moat N, de Belder MA, Blackman DJ, Duncan A, Banya W, et al. Transcatheter aortic valve implantation in the United Kingdom: temporal trends, predictors of outcome, and 6-year follow-up: a report from the UK Transcatheter Aortic Valve Implantation (TAVI) Registry, 2007 to 2012. Circulation. 2015;131: 1181-90.

33. Grant SW, Hickey GL, Ludman P, Moat N, Cunningham D, de Belder M, et al. Activity and outcomes for aortic valve implantations performed in England and Wales since the introduction of transcatheter aortic valve implantation. Eur J Cardiothorac Surg. 2016;49:1164-73.

34. Mack MJ, Brennan JM, Brindis R, Carroll J, Edwards F, Grover F, et al; STS/ ACC TVT Registry. Outcomes following transcatheter aortic valve replacement in the United States. JAMA. 2013;310:2069-77.

35. Holmes DR Jr, Brennan JM, Rumsfeld JS, Dai D, O'Brien SM, Vemulapalli S, et al. Clinical outcomes at 1 year following transcatheter aortic valve replacement. JAMA. 2015;313:1019-28.

36. Rodes-Cabau J, Webb JG, Cheung A, Dumont E, Feindel CM, Osten M, et al. Transcatheter aortic valve implantation for the treatment of severe symptomatic aortic stenosis in patients at very high or prohibitive surgical risk: acute and late outcomes of the multicenter Canadian experience. J Am Coll Cardiol. 2010;55: 1080-90.

37. Rodes-Cabau J, Webb JG, Cheung A, Ye J, Dumont E, Osten M, et al. Long-term outcomes after transcatheter aortic valve implantation: insights on prognostic factors and valve durability from the Canadian multicenter experience. J Am Coll Cardiol. 2012;60:1864-75.

38. Arnold SV, Reynolds MR, Lei Y, Magnuson EA, Kirtane AJ, Kodali SK, et al Predictors of poor outcomes after transcatheter aortic valve replacement: results from the PARTNER (Placement of Aortic Transcatheter Valve) trial. Circulation. 2014:129:2682-90.

39. Rodes-Cabau J, Mok M. Working toward a frailty index in transcatheter aortic valve replacement: a major move away from the "eyeball test" JACC Cardiovasc Interv. 2012;5:982-3.

40. Wenaweser P, Stortecky S, Schwander S, Heg D, Huber C, Pilgrim T, et al. Clinical outcomes of patients with estimated low or intermediate surgical risk undergoing transcatheter aortic valve implantation. Eur Heart J. 2013:34:1894-905.

41. Tamburino C, Barbanti M, D’Errigo P, Ranucci M, Onorati F, Covello RD, et al. 1-Year outcomes after transfemoral transcatheter or surgical aortic valve replacement: results rrom the Italian OBSERVANT Study. J Am Coll Cardiol. 2015;66: 804-12.

42. Piazza N, Kalesan B, van Mieghem N, Head S, Wenaweser P, Carrel TP, et al. A 3-center comparison of 1-year mortality outcomes between transcatheter aortic valve implantation and surgical aortic valve replacement on the basis of propensity score matching among intermediate-risk surgical patients. JACC Cardiovasc Interv. 2013:6:443-51.

43. Thyregod HG, Steinbrüchel DA, Ihlemann N, Nissen H, Kjeldsen BJ Petursson $\mathrm{P}$, et al. Transcatheter versus surgical aortic valve replacement in patients with severe aortic valve stenosis: 1-year results from the All-Comers NOTION Randomized Clinical Trial. J Am Coll Cardiol. 2015;65:2184-94.

44. Kodali S, Thourani VH, White J, Malaisrie SC, Lim S, Greason KL, et al. Early clinical and echocardiographic outcomes after SAPIEN 3 transcatheter aortic valve replacement in inoperable, high-risk and intermediate-risk patients with aortic stenosis. Eur Heart J. 2016;37:2252-62.

45. Mylotte D, Andalib A, Thériault-Lauzier P, Dorfmeister M, Girgis M, Alharbi W, et al. Transcatheter heart valve failure: a systematic review. Eur Heart J. 2015;36: 1306-27.

46. Dvir D. First look at long-term durability of transcatheter heart valves: assessment of valve function up to 10 years after implantation. Presented at the Annual Scientific Meeting of the EuroPCR, 2016. Paris, France.

47. Mylotte D, Osnabrugge RLJ, Windecker S, Lefèvre T, Jaegere P, Jeger R, et al. Transcatheter aortic valve replacement in Europe: adoption trends and factors influencing device utilization. J Am Coll Cardiol. 2013;62:210-9.

48. Merkel S, Eikermann M, Neugebauer EA, von Bandemer S. The transcatheter aortic valve implementation (TAVI) - a qualitative approach to the implementation and diffusion of a minimally invasive surgical procedure. Implement Sci. 2015;10:140.

49. Roques F, Nashef SA, Michel P. Regional differences in surgical heart valve disease in Europe: comparison between northern and southern subsets of the EuroSCORE database. J Heart Valve Dis. 2003;12:1-6.

50. Arnold SV, Spertus JA, Vemulapalli S, Dai D, O’Brien SN, Baron SJ, et al. Association of patient-reported health status with long-term mortality after transcatheter aortic valve replacement. Report from the STSACC TVT registry. Circ Cardiovasc Interv. 2015;8:e02875.
51. Allen LA, Rumsfeld JS. Can we predict who will be alive and well after transcatheter aortic valve replacement? Is that useful to patients? Circulation. 2014 129:2636-7.

52. Green P, Arnold SV, Cohen DJ, Kirtane AJ, Kodali S, Brown DL, et al. Relation of frailty to outcomes after transcatheter aortic valve replacement (from the PARTNER Trial). Am J Cardiol. 2015;116:264-9.

53. Herrmann HC, Han Y. Identifying patients who do not benefit from transcatheter aortic valve replacement. Circ Cardiovasc Interv. 2014;7:136-8.

54. Lindman BR, Alexander KP, O'Gara PT, Afilalo J. Futility, benefit, and trans catheter aortic valve replacement. J Am Coll Cardiol Interv. 2014;7:707-16.

55. O'Sullivan CJ, Wenaweser P, Ceylan O, Rat-Wirtzler J, Stortecky S, Heg D, et al Effect of pulmonary hypertension hemodynamic presentation on clinical outcomes in patients with severe symptomatic aortic valve stenosis undergoing transcatheter aortic valve implantation: insights from the new proposed pulmonary hypertension classification. Circ Cardiovasc Interv. 2015;8:e02358.

56. Puri R, Iung B, Cohen DJ, Rodés-Cabau J. TAVI or No TAVI: identifying patients unlikely to benefit from transcatheter aortic valve replacement. Eur Heart J. 2016;37:2217-25.

57. Allende R, Webb JG, Munoz-Garcia AJ, de Jaegere P, Tamburino C, Dager AE, et al. Advanced chronic kidney disease in patients undergoing transcatheter aortic valve implantation: insights on clinical outcomes and prognostic markers from a large cohort of patients. Eur Heart J. 2014;35:2685-96.

58. Ferro CJ, Chue CD, de Belder MA, Moat N, Wendler O, Trivedi U, et al. Impact of renal function on survival after transcatheter aortic valve implantation (TAVI): an analysis of the UK TAVI registry. Heart. 2015;101:546-52.

59. Gargiulo G, Capodanno D, Sannino A, Perrino C, Capranzano P, Stabile E, et al. Moderate and severe preoperative chronic kidney disease worsen clinical outcomes after transcatheter aortic valve implantation: meta-analysis of $4992 \mathrm{pa}-$ tients. Circ Cardiovasc Interv. 2015;8:e002220.

60. Kobrin DM, McCarthy FH, Herrmann HC, Anwaruddin S, Kobrin S, Szeto WY, et al. Transcatheter and surgical aortic valve replacement in dialysis patients: a propensity-matched comparison. Ann Thorac Surg. 2015;100: 1230-7

61. Nguyen TC, Babaliaros VC, Razavi SA, Kilgo PD, Guyton RA, Devireddy CM, et al. Impact of varying degrees of renal dysfunction on transcatheter and surgical aortic valve replacement. J Thorac Cardiovasc Surg. 2013;146:1399-406

62. Mok M, Nombela-Franco L, Dumont E, Urena M, DeLarochellière R, Doyle D, et al. Chronic obstructive pulmonary disease in patients undergoing transcatheter aortic valve implantation-insights on clinical outcomes, prognostic markers, and functional status changes. J Am Coll Cardiol Interv. 2013;6:1072-84.

63. Gilmore RC, Thourani VH, Jensen HA, Condado J, Binongo JN, Sarin EL, et al. Transcatheter aortic valve replacement results in improvement of pulmonary function in patients with severe aortic stenosis. Ann Thorac Surg. 2015;100: 2167-73.

64. Suri RM, Gulack BC, Brennan JM, Thourani VH, Dai D, Zajarias A, et al. Outcomes of patients with severe chronic lung disease who are undergoing transcath eter aortic valve replacement. Ann Thorac Surg. 2015;100:2136-46.

65. Makkar RR, Fontana GP, Jilaihawi H, Kapadia S, Pichard AD, Douglas PS, et al. Transcatheter aortic-valve replacement for inoperable severe aortic stenosis. $N$ Engl J Med. 2012;366:1696-704.

66. Mack MJ. Transcatheter aortic valve replacement in dialysis patients. Presented at the Annual Scientific Meeting of TCT, 2014. Washington, DC.

67. Arnold SV, Spertus JA, Lei Y, Green P, Kirtane AJ, Kapadia S, et al. How to define a poor outcome after transcatheter aortic valve replacement: conceptual framework and empirical observations from the placement of aortic transcatheter valve (PARTNER) trial. Circ Cardiovasc Qual Outcomes. 2013;6:591-7.

68. Puls M, Sobisiak B, Bleckmann A, Jacobshagen C, Danner BC, Hünlich M, et al. Impact of frailty on short- and long-term morbidity and mortality after transcatheter aortic valve implantation: risk assessment by Katz Index of activities of daily living. EuroIntervention. 2014;10:609-19.

69. Schoenenberger AW, Stortecky S, Neumann S, Moser A, Jüni P, Carrel T, et al. Predictors of functional decline in elderly patients undergoing transcatheter aortic valve implantation (TAVI). Eur Heart J. 2013;34:684-92.

70. Himbert D, Vahanian A. Transcatheter aortic valve replacement for patients with heart failure. Heart Fail Clin. 2015;11:231-42.

71. Tamburino C, Capodanno D, Ramondo A, Petronio AS, Ettori F, Santoro G, et al. Incidence and predictors of early and late mortality after transcatheter aortic valve implantation in 663 patients with severe aortic stenosis. Circulation. 2011;123:299-308. 
72. Schaefer U, Zahn R, Abdel-Wahab M, Gerckens U, Linke A, Schneider S, et al. Comparison of outcomes of patients with left ventricular ejection fractions $\leq 30 \%$ versus $\geq 30 \%$ having transcatheter aortic valve implantation (from the German Transcatheter Aortic Valve Interventions Registry). Am J Cardiol. 2015;115:656-63.

73. Urena M, Webb JG, Eltchaninoff H, Munoz-Garcia AJ, Bouleti C, Tamburino C, et al. Late cardiac death in patients undergoing transcatheter aortic valve replacement: incidence and predictors of advanced heart failure and sudden cardiac death. J Am Coll Cardiol. 2015;65:437-48.

74. Elmariah S, Palacios IF, McAndrew T, Hueter I, Inglessis I, Baker JN, et al. Outcomes of transcatheter and surgical aortic valve replacement in high-risk patients with aortic stenosis and left ventricular dysfunction: results from the Placement of Aortic Transcatheter Valves (PARTNER) trial (cohort A). Circ Cardiovasc Interv. 2013;6:604-14.

75. Amabile N, Agostini H, Gilard M, Eltchaninoff H, Iung B, Donzeau-Gouge P, et al. Impact of low preprocedural transvalvular gradient on cardiovascular mortality following TAVI: an analysis from the FRANCE 2 registry. EuroIntervention. 2014; 10:842-9.

76. Osnabrugge RL, Arnold SV, Reynolds MR, Magnuson EA, Wang K, Gaudiani VA, et al. Health status after transcatheter aortic valve replacement in patients at extreme surgical risk: results from the CoreValve U.S. trial. JACC Cardiovasc Interv. 2015;8:315-23.

77. Le Ven F, Freeman M, Webb J, Clavel MA, Wheeler M, Dumont E, et al. Impact of low flow on the outcome of high-risk patients undergoing transcatheter aortic valve replacement. J Am Coll Cardiol. 2013;62:782-8.

78. Herrmann HC, Pibarot P, Hueter I, Gertz ZM, Stewart WJ, Kapadia S, et al. Predictors of mortality and outcomes of therapy in low-flow severe aortic stenosis: a Placement of Aortic Transcatheter Valves (PARTNER) trial analysis. Circulation. 2013;127:2316-26.

79. Pibarot P, Dumesnil JG. Low-flow, low-gradient aortic stenosis with normal and depressed left ventricular ejection fraction. J Am Coll Cardiol. 2012;60: 1845-53.

80. Nombela-Franco L, Ribeiro HB, Urena M, Allende R, Amat-Santos I, DeLarochellière R, et al. Significant mitral regurgitation left untreated at the time of aortic valve replacement: a comprehensive review of a frequent entity in the transcatheter aortic valve replacement era. J Am Coll Cardiol. 2014;63: 2643-58.

81. Walther T, Kempfert J, Borger MA, Fassl J, Falk V, Blumenstein J, et al. Human minimally invasive off-pump valve-in-a-valve implantation. Ann Thorac Surg. 2008;85:1072-3.

82. Dvir D, Webb JG, Bleiziffer S, Pasic M, Waksman R, Kodali S, et al. Transcath eter aortic valve implantation in failed bioprosthetic surgical valves. JAMA. 2014;312:162-70.

83. Dvir D, Webb J, Brecker S, Bleiziffer S, Hildick-Smith D, Colombo A, et al Transcatheter aortic valve replacement for degenerative bioprosthetic surgical valves: results from the global valve-in-valve registry. Circulation. 2012;126: 2335-44.

84. Dvir D, Webb JG. Transcatheter aortic valve-in-valve implantation for patients with degenerative surgical bioprosthetic valves. Circ J. 2015;79:695-703.

85. Hamid NB, Khalique OK, Monaghan MJ, Kodali SK, Dvir D Bapat VN, et al. Transcatheter valve implantation in failed surgically inserted bioprosthesis. Review and practical guide to echocardiographic imaging in valve in valve procedures. JACC Cardiovasc Imaging. 2015;8:960-79.

86. Alnasser S, Cheema A, Kornowski R, Santos MS, Walther T, Latib A, et al. Matched comparison of Portico ${ }^{\circledR}$ and CoreValve ${ }^{\mathrm{TM}}$ self-expanding transcatheter heart valves for the treatment of failed surgical aortic bioprosthesis: insights from the valve in valve international data (VIVID) registry. Available at: http://heartvalvesociety.org/meeting/abstracts/2016/A37.cgi. Accessed November 28, 2016

87. Conradi L, Silaschi M, Seifferet M, Lubos E, Blankenberg S, Reichenspurner H, et al. Thranscatheter valve-in-valve therapy using 6 different devices in 4 anatomic positions: clinical outcomes and technical considerations. J Thorac Cardiovasc Surg. 2015;150:1557-67.

88. Thukkani AK, Klein MR, Mauney M, Kouchoukos N, Baker JN. Successful use of $20 \mathrm{~mm}$ SAPIEN 3 for valve in valve intervention within a $19 \mathrm{~mm}$ degenerated aortic biosprosthetic valve. Int J Cardiol. 2016;203:156-7.

89. Makkar RR, Fontana G, Jilaihawi H, Chakravarty T, Kofoed KF, de Backer O, et al. Possible subclinical leaflet thrombosis in bioprosthetic aortic valves. $N$ Engl J Med. 2015;373:2015-24. 